\title{
Modelling the variability of the sea-ice conditions in the Baltic Sea under different climate conditions
}

\author{
Jari Haapala, ${ }^{1}$ Arja Juottonen, ${ }^{2}$ Marika Marnela, ${ }^{1}$ Matti Leppäranta, ${ }^{1}$ Heikki Tuomenvirta ${ }^{2}$ \\ ${ }^{1}$ Department of Geophysics, P.O. Box 4 (Fabianinkatu 24 A), University of Helsinki, FIN-00014 Helsinki, Finland \\ ${ }^{2}$ Finnish Meteorological Institute, P.O. Box 503, FIN-00100 Helsinki, Finland
}

\begin{abstract}
The present and future ice conditions around 100 years from present in the Baltic Sea are examined by two 10 year integrations of an ice-ocean model. Results from atmospheric climate-model simulations constitute the atmospheric forcing, one representing present climate conditions (control simulation), and the other global warming due to $\mathrm{CO}_{2}$ doubling (scenario simulation). The present-day climatological ice conditions and the interannual variability were realistically reproduced by the ice-ocean model. The modelled range of the maximum annual ice extent in the Baltic was $190-420 \times 10^{3} \mathrm{~km}^{2}$ in the control simulation and $50-270 \times 10^{3} \mathrm{~km}^{2}$ in the scenario simulation. The range of the annual maximum level-ice thickness was $45-85$ and $20-58 \mathrm{~cm}$ in the control and scenario simulations, respectively.
\end{abstract}

\section{INTRODUCTION}

Baltic Sea ice time series show large natural variability in the onset of freezing, ice thickness, extent and break-up. The main reason for the interannual variation is the location of the Baltic Sea between the North Atlantic and Eurasian weather systems. The overall evolution of the ice season is well correlated with the North Atlantic Oscillation (NAO) winter index. Westerlies bring moist, warm air masses over the Baltic, making the ice conditions appear mild. In contrast, when the continental weather pattern prevails, the ice season is mostly severe. The local climatological characteristics of the ice conditions, on the other hand, are more dependent on the regional weather conditions.

Previous modelling (Omstedt and Nyberg, 1996; Haapala and Leppäranta, 1997) and time-series studies (cf. Tinz, 1996) have shown that the ice conditions in the Baltic are largely controlled by the atmospheric forcing, with even minor changes in air temperature leading to large changes in ice extent and thickness. The impact of global climate change on regional characteristics could not be properly investigated until recently, when accurate atmospheric model simulations became available. Rummukainen and others (2001) used a regional atmospheric model (RCAl) to estimate climate warming in the Baltic Sea region. Their results are based on dynamic downscaling of global atmospheric general circulation model simulations. These constitute the forcing fields in this study.

In this paper we present estimates of the variability of the ice conditions in the Baltic Sea. We use a multi-ice-class numerical sea-ice model which takes into account the deformation processes of the ice pack. We simulate the evolution of the ice pack during a 10 year period and calculate the variability of the sea-ice conditions on seasonal and interannual time-scales. A similar study has been conducted by Meier (2000) whose results will be compared with the present results.

\section{MODEL DESGRIPTION}

In geophysical modelling, sea ice is treated as a continuum of several ice floes. The apparent ice conditions are a result of thermodynamic and dynamic processes. The spatial icethickness variability in a specific region can be described by an ice-thickness distribution function (Thorndike and others, 1975). The evolution of an ice-thickness distribution is due to advection, thermodynamic growth or melt and production of deformed ice and open water. In this work, we use a numerical model which solves the momentum balance of sea ice, the ice-thickness redistribution and the thermodynamic growth and decay of ice. It is coupled to a thermodynamical ocean surface layer model. A detailed description of the model is presented in Haapala and Leppäranta (1996) and Haapala (2000). The internal stress of ice is calculated in accordance with viscous-plastic rheology. The ice-strength parameter is constant and the momentum balance is solved by over-relaxation (Hibler, 1979). Thermodynamic growth and melt of ice is calculated according to the Semtner zero-level model (Semtner, 1976). The ice-thickness redistribution model is based on physical ice classes. The principal classification is a separation of the pack ice into undeformed and deformed ice types. Undeformed is subdivided into level ice and lead ice. The latter was introduced to describe new-ice growth. In the model, divergent ice motion decreases ice compactness and new-ice growth occurs if the initially ice-free fraction (lead) freezes. Deformed ice is separated into rafted ice, rubble ice (or hummocked ice) and ridged ice. Inherent evolution equations are used for each ice class. The mass flux between these ice classes is dependent on ice compactness, thickness and velocity divergence. The model has been verified against observed ice-thickness, concentration and velocity data (Haapala and Leppäranta, 1996; Leppäranta and others 1998; Haapala, 2000).

The resolution of the numerical grid is $10^{\prime}$ in latitude and 

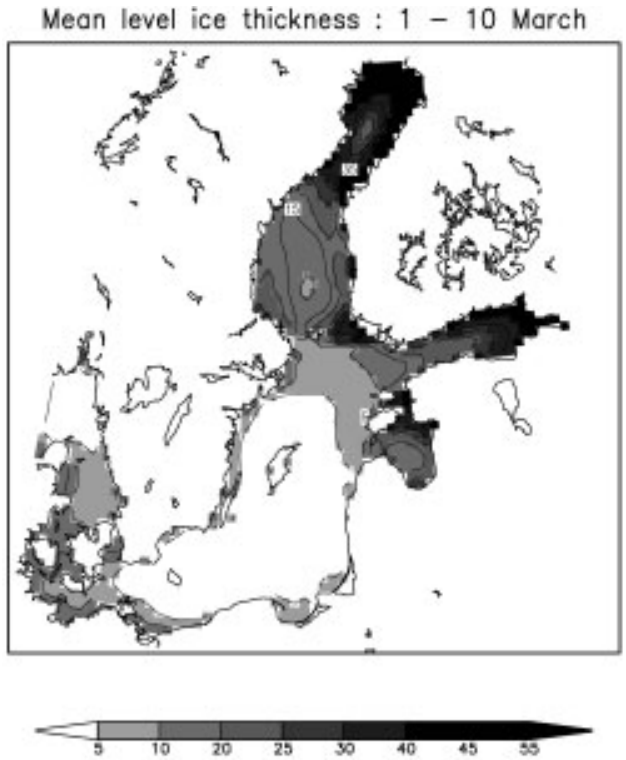

Mean ridged ice thickness : 1 - 10 March
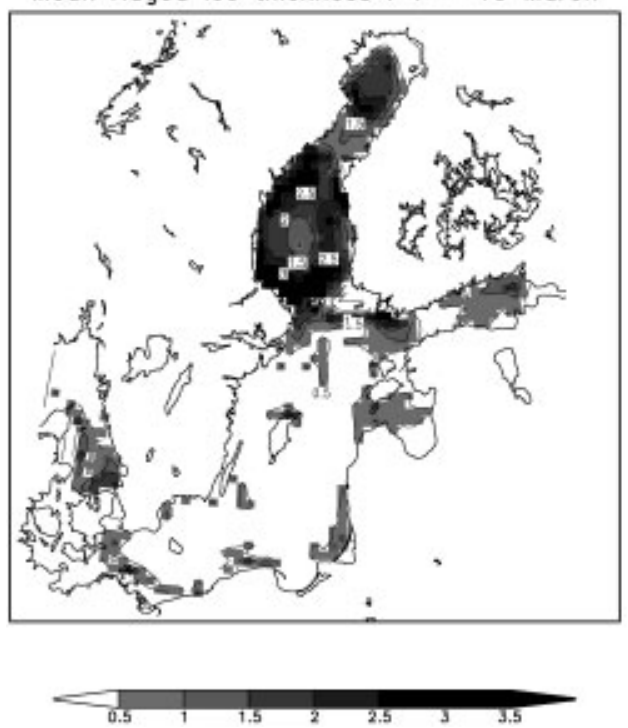

Mean level ice thickness : 1 - 10 March
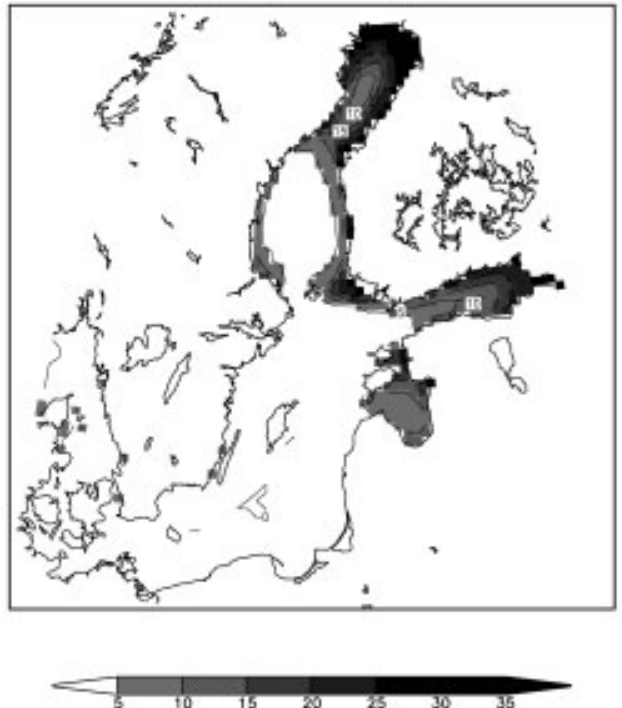

Mean ridged ice thickness : 1 - $10 \mathrm{March}$ (Sce)
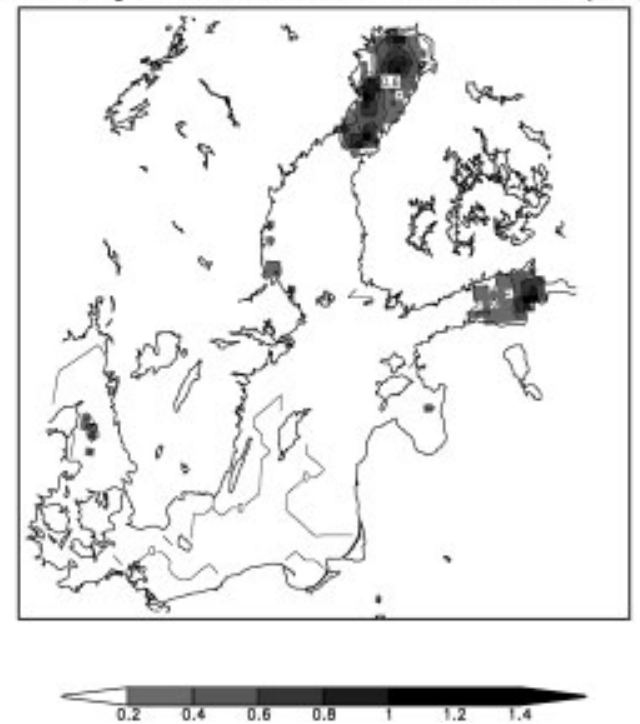

Fig. 1. Modelled mean level-and ridged-ice thickness, 1-10 March, for control (left panels) and scenario simulation(right panels).

Units of the contour lines are centimeters.

$20^{\prime}$ in longitude, and the domain covers the whole Baltic Sea. The open boundary at Skagerrak $\left(9^{\circ} 30^{\prime} \mathrm{E}\right)$ is closed in the model. Vertically, the thermodynamics of the ocean surface layer model are solved in four equally spaced levels of sigma coordinates. The model topography is based on the Institut für Ostseeforschung database (Seifert and Kayser, 1995).

The model is forced by fluxes of heat, moisture, radiation and momentum. The parameterization methods of the fluxes and other model parameters are identical to those used in Haapala (2000). The initial conditions for the sea-water temperature and salinity were calculated from the 1961-90 climatology (Haapala and Alenius, 1994).

\section{ATMOSPHERIC FORGING}

The atmospheric forcing for the ice model was obtained from the dynamic downscaling of a coupled global atmosphericocean general circulation model (AOGCM). The downscaling for the Baltic Sea region was produced in the framework of the Swedish Regional Climate Modelling Programme of the Rossby Center, Norrköping (Rummukainen and others, 2001), where a regional atmospheric climate model ( $\mathrm{RCAl}$ )covering northern Europe has been developed. The boundary conditions of the regional model were taken from the Hadley Centre for Climate Prediction and Research (Bracknell, U.K.) AOGGM model (HadCM2; see Johns and others, 1997).

The Hadley Centre climate simulations consist of two 240 year numerical experiments, one representing the present climate (control simulation), and the other a transient simulation using a scenario on the increase of greenhouse gases (scenario simulation). The Rossby Center simulations (Rummukainen and others, 2001) are based on two 10 year time slices of the global-model control and scenario runs. The increase of the global mean temperature from the control run to the scenario run is $2.6^{\circ} \mathrm{C}$. Such a warming due to enhanced greenhouse gases is expected to occur at the end of the 21st century.

\section{RESULTS}

The evolution of the sea-ice conditions was simulated during the 10 year control and scenario periods. In this section we 

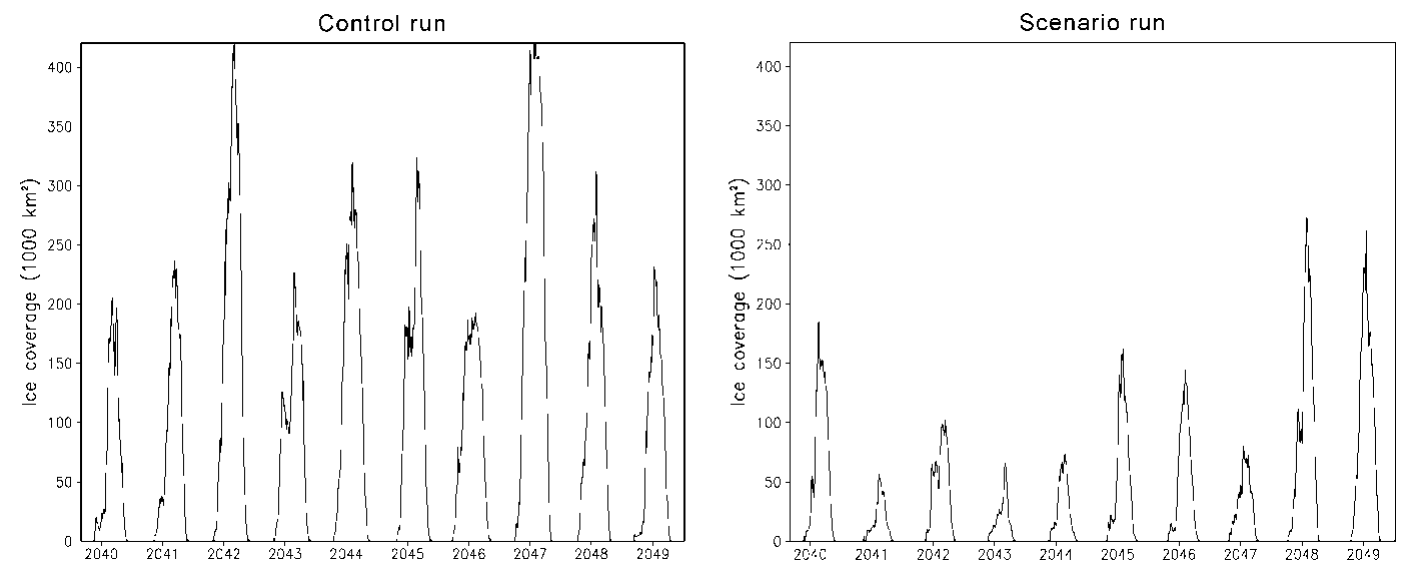

Fig. 2. Time series for the modelled ice extent for control (left panel) and scenario simulation (right panel).

analyze the model-derived mean sea-ice conditions and the variability of the thermodynamically and dynamically produced ice. The control simulation reflects ice conditions in a slightly colder climate than presently observed, while the scenario simulation is supposed to represent future ice conditions around the year 2100 .

\section{Mean conditions}

Mean level-ice thickness of the simulated ice winters for the period 1-10 March is presented in Figure 1. In the control simulation, ice covers all the northern sub-basins and the Danish straits. Ice thickness varies from $70 \mathrm{~cm}$ in the Bay of Bothnia to $10 \mathrm{~cm}$ in the southern regions. Interannual variability of the maximum ice thickness is $45-85 \mathrm{~cm}$ (s.d. $9 \mathrm{~cm}$ ) in the northern regions. In the scenario simulation, the extent of the ice-covered area and the thickness of ice is much reduced. Only the Bay of Bothnia is fully ice-covered. Ice is also formed in the coastal areas of the Bothnian Sea, in the eastern parts of the Gulf of Finland and the Gulf of Riga. Ice thickness is about $20 \mathrm{~cm}$ less than in the control simulation. The fast-ice region is prescribed in the model (Haapala and Leppäranta, 1996), so there is no change in its extent. The model-produced maximum annual ice thickness of the fast ice in the northern region is $20-58 \mathrm{~cm}$ (s.d. $4 \mathrm{~cm}$ ) in the scenario simulation. The length of the ice season is reduced from 207 days to 172 days in the Bay of Bothnia(Oulu) and from 156 days to 110 days in the Gulf of Finland(Kotka).

Where mean ridged-ice thickness is concerned, regions of maximum values are found between the fast-ice boundary and the centers of the basins (Fig. 1). The maximum gridded-mean ridged-ice thickness is $2-4 \mathrm{~cm}$ in the control simulation, while in the scenario run it is $1.5 \mathrm{~cm}$.

\section{Interannual variation}

The interannual variation of the ice winter severity is shown in Figure 2 which depicts the modelled ice coverage. In the control simulation there are two occasions when the maximum ice extent reaches $420 \times 10^{3} \mathrm{~km}^{2}$, which means that the whole Baltic is ice-covered. The mean annual maximum ice extent is $290 \times 10^{3} \mathrm{~km}^{2}$, and the absolute minimum is $190 \times 10^{3} \mathrm{~km}^{2}$, with a standard deviation of $80 \times 10^{3} \mathrm{~km}^{2}$. In the scenario simulation the interannual variation is similar, although the sea-ice coverage is much less. An important finding is that ice is formed in each simulation winter. The mean ice extent is $190 \times 10^{3} \mathrm{~km}^{2}$, and the range is $50-270 \times 10^{3} \mathrm{~km}^{2}$ (s.d. $80 \times 10^{3} \mathrm{~km}^{2}$ ).

Climatological Baltic Sea ice conditions have also been modelled by Meier (2000), who employed the same atmospheric forcing data. The numerical model he used, however, is a primitive-equation ocean model (Webb and others, 1997) coupled to an elastic-plastic ice model (Hunke and Dukowicz, 1997; Meier and others, 1999). Overall, quantities such as ice extent and level-ice thickness, as well as their interannual variations, are very similar in both model simulations. It is remarkable that these two independent models produce similar results. This increases the reliability of future projections of ice conditions in the Baltic Sea.

\section{Variability of ice production}

Seasonal cycles of ice production of level, lead and deformed ice (sum of ridged-, rafted- and rubble-ice classes) in the Bay of Bothnia are shown in Figure 3. The highest growth rates are observed during early winter, when the ice is thin. The maximum level-ice growth rates are $3-4 \mathrm{~cm} \mathrm{~d}^{-1}$. The mean growth rate during the winter months is $0.42 \mathrm{~cm} \mathrm{~d}^{-1}$, with a standard deviation of 0.13 . Conversion of these values to energy units means that the average heat loss over the whole Bothnian Sea basin is about $15 \mathrm{~W} \mathrm{~m}^{-2}$, and the maximum about $150 \mathrm{~W} \mathrm{~m}^{-2}$. Locally, these values can be larger. At the beginning of April the mean thermodynamic growth rate becomes negative. The melting rates can exceed $5 \mathrm{~cm} \mathrm{~d}^{-1}$.

The seasonal cycles of level-ice production in the control and scenario simulation are rather similar. The maximum growth rate of the scenario simulation is almost as large as in the control simulation, while the mean growth rate is only $0.21 \mathrm{~cm} \mathrm{~d}^{-1}$. The maximum thermodynamic growth rates occur during the initial freezing of sea water. Typically, these situations are driven by large sensible- and latent-heat fluxes when cold and dry air is advected over the sea. The growth rates are also partially affected by the other components of the heat budget, especially snow cover which reduces growth rates due the insulation effect. However, the effect of the snow cover is similar in all simulations because the snow-precipitation rate remains the same in the control and scenario simulations (Meier, 2000).

Positive lead-ice production rates indicate new-ice growth due to the divergent ice motion. Negative production rates are due to the thermodynamic and mechanical redistribution of lead ice to the level- and deformed-ice classes. The range of 

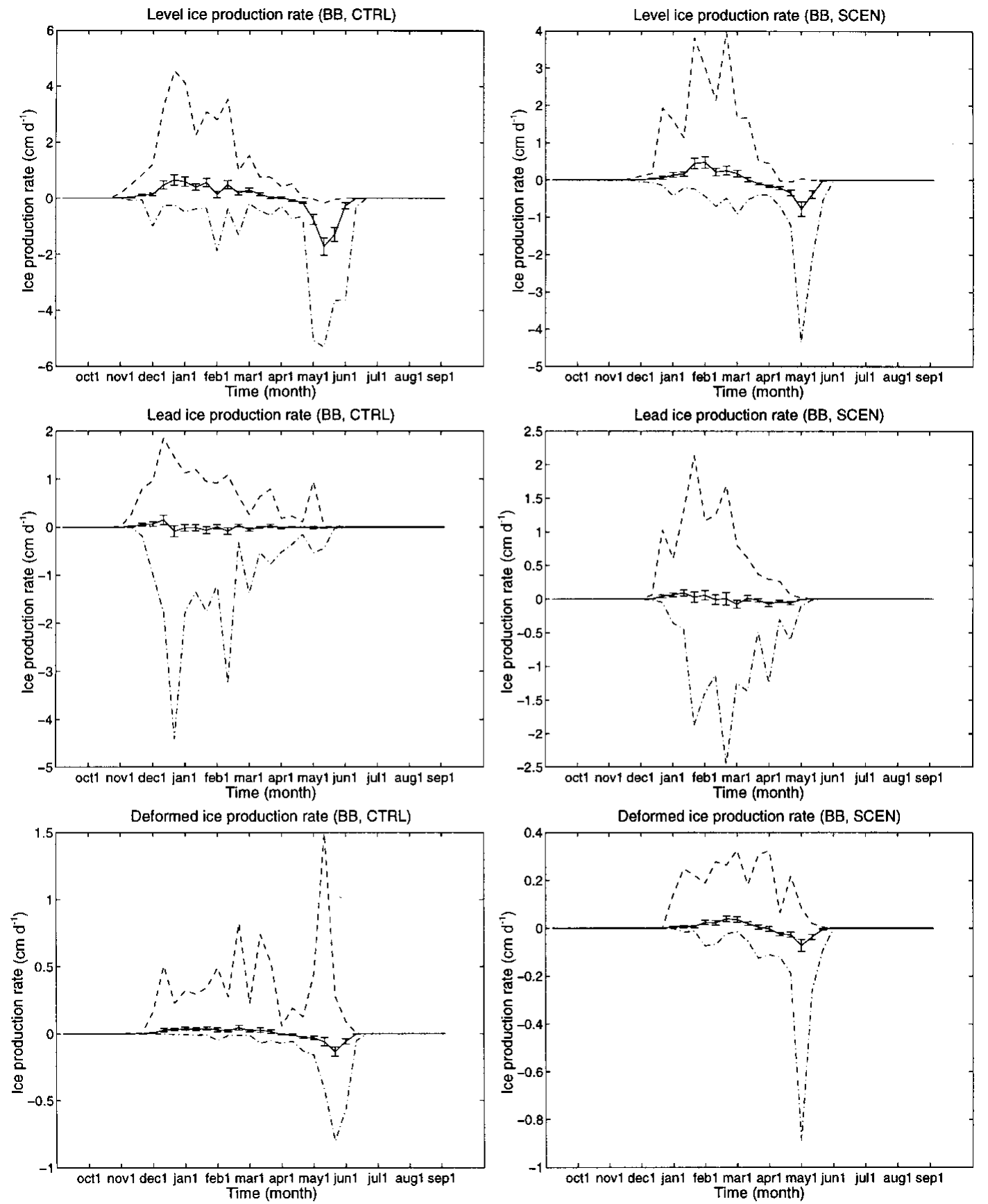

Fig. 3. Production rates of the level, lead and deformed ice integrated over the Bay of Bothnia area. Solid lines indicate weekly mean values, vertical bars their standard deviation and the dotted lines the maximum and minimum values.

the lead-ice production is large in both the control and scenario simulations. The maximum production rates are $1-$ $2 \mathrm{~cm} \mathrm{~d}^{-1}$, and the maximum decay rates are -2 to $-4 \mathrm{~cm} \mathrm{~d}^{-1}$. The most extreme values are observed during early winter. The weekly means of the lead-ice production are close to zero, which means that once the lead ice is generated it is redistributed to the other ice classes within a few weeks.

Deformed-ice production rates indicate the mechanical production of ice during convergent ice motion. During early and mid-winter the deformed-ice production rate is positive. It is rather low, only $0.03 \mathrm{~cm} \mathrm{~d}^{-1}$ on average, in the control simulation. The maximum growth rates are $0.25-1 \mathrm{~cm} \mathrm{~d}^{-1}$. In the scenario simulation the corresponding growth rates are $0.015 \mathrm{~cm} \mathrm{~d}^{-1}$ on average, and the maxima $0.2-0.3 \mathrm{~cm} \mathrm{~d}^{-1}$.

The modelled deformed-ice growth rates are low compared to the observed Baltic Sea statistics (Lewis and others, 1993) or to the previous modelling studies (Haapala and Leppäranta, 1996; Haapala, 2000). The underestimation of the deformed-ice growth is probably due to inaccuracies in the wind forcing. According to Räisänen and Döscher (1999), the northwest-southeast surface pressure gradient of the Hadley Centre global climate model is lower than observed. Such bias leads to an underestimation of the surface winds of the regional model and thus to an underestimation of the modelled deformed-ice growth.

\section{GONGLUSIONS}

A numerical model has been used to estimate the interannual variation of the ice conditions in the Baltic Sea. The ice model was forced with regional atmospheric climate-model data which consist of two 10 year periods roughly representing the present and future climate. The ice model produced large 
interannual variations in all model variables. The modelled range of the annual ice extent in the Baltic was 190$420 \times 10^{3} \mathrm{~km}^{2}$ in the control simulation and $50-270 \times 10^{3} \mathrm{~km}^{2}$ in the scenario simulation. The interannual variation of the annual maximum level-ice thickness was 45-85 and 20$58 \mathrm{~cm}$ in the control and scenario simulations, respectively. These values are consistent with the observed range of ice extent and thickness in the Baltic (SMHI and FIMR, 1982; Seinä and Palosuo, 1996) and the numerical simulations of Meier (2000).

The mean thermodynamic growth rate of level ice during the winter months was $0.42 \mathrm{~cm} \mathrm{~d}^{-1}$ in the control simulation and $0.21 \mathrm{~cm} \mathrm{~d}^{-1}$ in the scenario simulation. The maximum thermodynamic growth rates were about $3-4 \mathrm{~cm} \mathrm{~d}^{-1}$ in both simulations. This implies that although the thermodynamic ice production is much less in the warmer climate, the most intensive freezing is similar.

The modelled deformed-ice production rates were low compared to the observed statistics and previous model results. This is mainly due to the underestimated surface winds in the atmospheric model data used to drive the seaice-ocean model. In particular, the lack of intensive synopticscale pressure fields leads to a serious underestimation of deformed-ice production.

\section{ACKNOWLEDGEMENTS}

The Rossby Center is acknowledged for providing the atmospheric data, and the Finnish Center for Scientific Computing for providing computing facilities. This work was supported by the FIGARE programme of the Academy of Finland and the Ministry of Finnish Trade and Industry.

\section{REFERENCES}

Haapala, J. 2000. On the modelling of ice-thickness redistribution. F. Glaciol., 46(154), 427-437.

Haapala, J. and P. Alenius. 1994. Temperature and salinity statistics for the northern Baltic Sea, 1961-69. Finn. Mar. Res. 262, 51-121.

Haapala, J. and M. Leppäranta. 1996. Simulating the Baltic Sea ice season with a coupled ice--ocean model. Tellus, 48A(5), 622-643.
Haapala, J. and M. Leppäranta. 1997. The Baltic Sea ice season in changing climate. Boreal Environ. Res., 2(1), 93-108.

Hibler, W. D., III. 1979. A dynamic thermodynamic sea ice model. f. Phys. Oceanogr., 9 (7), 815-846.

Hunke, E. C. and J. K. Dukowicz. 1997. An elastic-viscous-plastic model for sea ice dynamics. F. Phys. Oceanogr., 27(9), 1849-1867.

Johns, T. C. and 7 others. 1997. The second Hadley Centre coupled oceanatmosphere GCM: model description, spinup and validation. Climate Dyn., 13(2), 103-134.

Leppäranta, M., Yan Sun and J. Haapala. 1998. Comparisons of sea-ice velocity fields from ERS-1 SAR and a dynamic model. f. Glaciol., 44(147), 248-262.

Lewis, J. E., M. Leppäranta and H. B. Granberg. 1993. Statistical properties of sea ice surface topography in the Baltic Sea. Tellus, 45A(2), 127-142.

Meier, H. E. M. 2000. First results of scenario simulations using a coupled ice-ocean model for the Baltic Sea. SWECLIM Newsletter 7-8, 34-45.

Meier, H. E.M., R. Döscher, A. C. Coward, J. Nycander and K. Döös. 1999. $R C O-$ Rossby Centre regional Ocean climate model: model description (version 1.0) and first results from the hindcast period 1992/93. Norrköping, Swedish Meteorological and Hydrological Institute. (SMHI Reports. Hydrology and Oceanography 26.)

Omstedt, A. and L. Nyberg. 1996. Response of Baltic sea ice to seasonal, interannual forcing and climate change. Tellus, 48A(5), 644-662.

Räisänen, J. and A. Döscher. 1999. Simulation of present-day climate in Northern Europe in the HadCM2 OAGCM. Norrköping, Swedish Meteorological and Hydrological Institute. (SMHI Report 84.)

Rummukainen, M. and 7 others. 2001. A regional climate model for northern Europe: model description and results from the downscaling of two GCM control simulations. Climate Dyn. 17, 339-358.

Seifert, T. and B. Kayser. 1995. A high resolution spherical grid topography of the Baltic Sea. Warnemünde, Institut für Ostseeforschung, 74-88. (Marine Science Reports 9.)

Seinä, A. and E. Palosuo. 1996. The classification of the maximum annual extent of ice cover in the Baltic Sea 1720-1995. Meri 27, 79-91.

Semtner, A. J., Jr. 1976. A model for the thermodynamic growth of sea ice in numerical investigations of climate. 7. Phys. Oceanogr., 6(5), 379-389.

Swedish Meteorological and Hydrological Institute (SMHI) and Finnish Institute of Marine Research (FIMR). 1982. Climatological ice atlas for the Baltic Sea, Kattegat, Skagerrak and Lake Vänern (1963-1979). Norrköping, Swedish Meteorological and Hydrological Institute; Finnish Institute of Marine Research.

Thorndike, A. S., D. A. Rothrock, G. A. Maykut and R. Colony. 1975. The thickness distribution of sea ice. 7. Geophys. Res., 80 (33), 4501-4513.

Tinz, B. 1996. On the relation between annual maximum extent of ice cover in the Baltic Sea level pressure as well as air temperature field. Geophysica, 32(3), 319-341.

Webb, D. J., A. C. Coward, B. A. de Cuevas and C. S. Gwilliam. 1997. A multiprocessor ocean circulation model using message passing. 7. Atmos. Oceanic Technol., 14, 175-183. 